\title{
Structural Approaches of Polyethylene Environmental Stress-Crack Resistance
}

\author{
J. Cazenave', B. Sixou', R. Seguela² \\ 1 Groupe d'étude de métallurgie physique et de physique des matériaux, \\ Institut national des sciences appliquées de Lyon, bâtiment Blaise Pascal, 20, avenue Albert Einstein, 69621 Villeurbanne - France. \\ 2 Laboratoire structure et propriétés de l'état solide, bâtiment C6, Université de Lille 1, 59655 Villeneuve d'Ascq - France \\ email: bruno.sixou@insa-lyon.fr - julien.cazenave@insa-lyon.fr - roland.seguela@univ-lille 1.fr
}

Résumé - Approches structurales de la fissuration sous contrainte du polyéthylène en milieu tensio-actif - Ce travail est une contribution à la compréhension et la prédiction du comportement à long terme du polyéthylène en relation avec l'architecture moléculaire. L'exploration de la microstructure semi-cristalline et de la topologie moléculaire constituée de chaînes liantes intercristallines et de boucles de repliement constitue l'objectif majeur du travail. Une cristallisation fractionnée en deux étapes a été utilisée pour la séparation des espèces pouvant facilement cristalliser par repliement régulier de celles qui ne peuvent pas. Le taux de déformation naturel qui se développe au-delà du seuil d'écoulement plastique en traction uni-axiale s'est avéré très sensible à la topologie moléculaire par le biais de la fragmentation lamellaire et du dépliement de chaîne. La diffusion des rayons $\mathrm{X}$ aux petits angles a fourni de précieux renseignements semi-quantitatifs sur la régularité d'empilement de la microstructure lamellaire. Les données issues des trois approches révèlent des corrélations avec l'architecture moléculaire en bonne concordance avec l'évolution de la résistance à la fissuration sous contrainte. Ces corrélations sont discutées en termes de cinétique de cristallisation et de topologie moléculaire. Un résultat pratique de ce travail est l'accès à des outils prédictifs fiables pour la résistance à la fissuration sous contrainte.

\begin{abstract}
Structural Approaches of Polyethylene Environmental Stress-Crack Resistance - This work was aimed at understanding and predicting of the long-term mechanical behavior of polyethylene in relation to molecular architecture. An insight into the semi-crystalline microstructure and the chain topology consisting of intercrystalline tie chains and loose folding loops was the main objective of the study. A two-stage crystallization segregation was used for separating the chain species which can easily crystallize by regular folding from those which cannot. The natural draw ratio that develops beyond the yield point proved to be a highly sensitive parameter for probing the chain topology via the crystalline lamella fragmentation and chain unfolding under tensile drawing. Small-angle X-ray scattering provided semi-quantitative evaluation of the stacking disorder of the lamellar microstructure. The data from the three approaches provided correlations with chain architecture in very good agreement with the stress crack resistance dependency. These correlations were discussed in terms of crystallization kinetics and molecular topology. A practical issue of the work is to provide relevant tools for predicting stress cracking resistance.
\end{abstract}




\section{INTRODUCTION}

During the last two decades, polyethylene-based materials (PE) have been increasingly used in application domains demanding long life-time in service, such as pipes for gas distribution or fuel tanks for land vehicles [1]. The reason is that new generation PEs with tailored-cut molecular architecture have much better long-term behavior than their 50-yearsold parents. Preserving a high stiffness, i.e. optimum crystal content, is a concomitant challenge for the manufacturing of self-supporting structures. Such materials are competing with metals owing to their specific properties such as low energy consumption processing, low density, corrosion resistance, good impact strength as well as easy recycling.

Slow crack growth is the major failure mechanism of PE under stress below the yield point. This phenomenon determines the life-time in service. Localized plastic yielding occurs about stress-nucleated cavities in the inter-crystallite amorphous layers $[2,3]$. This is accompanied with fragmentation and partial chain unfolding of the crystalline lamellae, a process which obeys the fibrillar transition model described by Peterlin $[4,5]$. The initial damage gradually becomes a craze, i.e. a narrow crack bridged by numerous microfibrils which prevent the crack opening [6, 7]. The resistance to stress cracking is generally ascribed to the tensile resistance of the microfibrils. It is mainly governed by the concentration of the load-bearing inter-crystalline tie molecules linking the crystal blocks in the microfibrils $[8,9]$ that slow down the crack opening.

A great problem for evaluating and certificating new PE materials for pipe or tank applications is that homologation tests for stress-crack resistance must be conducted for very long times, e.g. several months in the case of the standard pipe pressure test. Quick evaluation methods would be very useful for the purpose of mechanical behavior prediction. In parallel, a precise knowledge of the stress cracking mechanisms at a molecular scale is necessary for providing adequate solutions to the problem.

In the search of quick evaluation methods, several authors have investigated cold-drawn samples for simulating the fibrillated material in the crack tip region. The creep behavior of such drawn samples revealed very good correlations with life-time data, at both macroscopic $[10,11]$ and microscopic scales [12]. Although elegant, these methods proved to be not sensitive enough to discriminate materials of very long lifetime [10-12].

This paper addresses the question of different methods for determining PE ability to develop tie molecules, with the goal of predicting the environmental stress crack resistance, one of the most widely used method for long-term mechanical property evaluation $[10,12]$. Three approaches have been put to the test in that aim. The first approach is the stepwise isothermal segregation that enables separating molecular species with respect to the crystallization capabilities as a function of undercooling, in PE-based polymers [13, 14]. The second approach is based on the natural draw ratio which determines the capability of fragmentation and chain unfolding of the crystalline lamellae, beyond the yield point. The third approach is small-angle X-ray scattering that provides deep insight into the stacking perfection of the semicrystalline lamellar microstructure. The whole study has been carried out on a collection of polymers having various molecular architectures regarding co-unit content and distribution, as well as molar weight distribution.

\section{EXPERIMENTAL METHODS}

Number-average and weight-average molar weights, $M_{n}$ and $M_{w}$, were determined by size exclusion chromatography using ortho-di-chloro-phenol. The average hexene co-unit concentration, $\xi$, was assessed from the methyl group content measured by $\mathrm{H}^{1}$ Nuclear Magnetic Resonance, in consideration of the methyl and vinyl chain ends.

Density, $\rho$, was measured in a water-alcohol gradient column calibrated with floating glass beads at $23^{\circ} \mathrm{C}$. The weight crystallinity, $X c$, was determined from differential scanning calorimetry, using a melting enthalpy $\Delta H_{f}^{\circ}=270$ $\mathrm{J} / \mathrm{g}$ for perfectly crystalline PE [15]. The volume crystallinity, $\phi_{c}$, was assessed from $\phi_{. c .}=X_{. c} \rho / \rho_{c}$, where $\rho_{. c}=1000 \mathrm{~g} / \mathrm{cm}^{3}$ is PE perfect crystal density [15].

The Environmental Stress Cracking Resistance (ESCR) was determined according to the standard Bell test [ASTM Norm D1693) which consists in clamping rectangular samples into bend position. Ten pieces of every material were tested in a $100 \%$ Igepal bath at room temperature.

Stepwise Isothermal Segregation (SIS) of polymer crystallization has been applied following a two-step procedure, using a DSC7 Perkin-Elmer apparatus. After melting at $210^{\circ} \mathrm{C}$ for $10 \mathrm{~min}$, the $7-\mathrm{mg}$ samples were rapidly cooled down to $120^{\circ} \mathrm{C}$ for isothermal crystallization during 4 hours. Then, the material was cooled down to room temperature at cooling rate of $10^{\circ} \mathrm{C} / \mathrm{min}$ in order to crystallize the remaining crystallizable part. This procedure resulted from a meticulous optimization of both the temperature an the duration of the high temperature isothermal step in order to get a physical segregation for all the polymers of the study, within reasonable time. Melting was subsequently recorded by heating at $10^{\circ} \mathrm{C} / \mathrm{min}$. Most of the materials displayed a double-hump melting endotherm corresponding to two polymer species that crystallized during each of the two crystallization steps.

The first isothermal crystallization step at low undercooling is expected to result in predominant chain-folding and very few inter-crystalline tie chains. This concerns medium length chains with no or very few co-units. The next crystallization step during the subsequent cooling of the material will proceed at larger undercooling involving a high rate of random chain-folding and tie molecules. This concerns 
co-unit rich chains as well as very long chains without co-units. For the sake of an illustration, the two crystallization stages can be respectively associated with regime II and regime III in Hoffman's growth theory [16, 17]. The SIS ratio, defined as the ratio of the lower melting peak enthalpy to the total melting enthalpy, represents the proportion of chains that preferentially generate random folds and tie chains.

The natural draw ratio (NDR) results from the sudden and unstable plastic deformation that occurs beyond the yield point, i.e. plastic necking, which mainly depends on the nature of the material [18]. The NDR was determined from the ratio of the sample cross section prior and after necking, at room temperature. The samples of gauge length $24 \mathrm{~mm}$ and width $4 \mathrm{~mm}$ were drawn at a cross-head speed of $10 \mathrm{~mm} / \mathrm{min}$, and the neck was propagated up to a length of $5 \mathrm{~cm}$ for all samples.

The unique theoretical modeling for the NDR for semicrystalline polymers is due to Tarin and Thomas [19] who proposed to account for the fragmentation of the crystalline lamellae and the concomitant chain unfolding, according to Peterlin's model. The quantitative approach notably considers the volume fraction of the material that is concerned with chain unfolding and the local draw ratio associated with every chain unfolding event. Accordingly, NDR would be mainly sensitive to the chain topology that hinders both the lamella fragmentation and the chain-unfolding.

Small-angle X-ray scattering (SAXS) results from the regular stacking of the crystalline lamellae and amorphous layers. This method is able to provide indirect information on the crystallization kinetics and the resulting chain topology through the determination of the average value and distribution of the crystal thicknesses. Experiments were carried on a laboratory bench equipped with a two-dimensional CCD camera from Roper Scientific. The $\mathrm{Cu}-\mathrm{K} \alpha_{1}$ radiation, $\lambda=0.154 \mathrm{~nm}$, was selected from a Rigaku rotating anode and collimated owing to a specific point-focusing Goebel mirror from Xenocs. The patterns were corrected for the background scattering and for the geometry and intensity distortions of the CCD detector. The long period of the lamellar stacking, $L_{p}$, was computed from the Bragg analysis of the Lorentzcorrected intensity profile as a function of the scattering vector, $q=4 \pi \sin \theta / \lambda$. The most probable crystal lamella and amorphous layer thickness, $L_{c}$ and $L_{a}$ respectively, were assessed from the relations $L_{c}=\phi_{c} L_{p}$ and $L_{a}=L_{p}-L_{c}$ which assume a much larger lateral extent of the crystalline lamellae as compared with their thickness. The lamellar stacking disorder has been checked via Hosemann's linear paracrystalline model [20] which predicts the SAXS behavior of a uni-dimensional stacking of two kinds of lamellae having different electron densities. The paracrystalline disorder of the model consists in the thickness distribution of each lamella population, and the extent of the lamella stacks giving rise to coherent scattering. The layer thickness distributions are described by Reinhold's distribution function [21]. The disorder parameters, $\gamma_{c}$ and $\gamma_{a}$, control both the breadth and the skew of the distributions, whereas $N$ is the number of lamellar elements diffusing coherently. The

TABLE 1

Molecular and physical characteristics of the PE samples: density, $\rho$; average hexene co-unit concentration, $\xi$; number-average and weight-average molar weights, $M_{n}$ and $M_{w}$; crystal weight fraction, $X_{c}$; most probable crystal thickness, $L_{c}$; thickness distribution parameter, $\gamma$; number of coherently scattering lamellae, $N$

\begin{tabular}{|c|c|c|c|c|c|c|c|c|}
\hline Materials & $\rho\left(\mathrm{g} / \mathrm{cm}^{3}\right)$ & $\xi(\operatorname{mole} \%)$ & $M_{n}(\mathrm{kDa})$ & $M_{w}(\mathrm{kDa})$ & $X_{c}(\%)$ & $L_{c}(\mathrm{~nm})$ & $\gamma$ & $N$ \\
\hline Cr11 & 0.961 & 0.0 & 15.2 & 108 & 72 & 15.8 & 0.32 & 30 \\
\hline Cr12 & 0.960 & 0.0 & 16.8 & 116 & 72 & 15.8 & 0.32 & 30 \\
\hline Cr13 & 0.959 & 0.0 & 18.1 & 129 & 72 & 15.7 & 0.33 & 25 \\
\hline Cr14 & 0.958 & 0.0 & 14.9 & 125 & 71 & 15.5 & 0.33 & 20 \\
\hline Cr15 & 0.954 & 0.2 & 19.9 & 187 & 67 & 13.8 & 0.33 & 20 \\
\hline Cr16 & 0.951 & 0.2 & 16.7 & 131 & 65 & 12.8 & 0.35 & 15 \\
\hline $\mathrm{Cr} 21$ & 0.959 & 0.0 & 15.0 & 229 & 71 & 15.8 & 0.32 & 15 \\
\hline $\mathrm{Cr} 22$ & 0.957 & 0.0 & 15.2 & 203 & 70 & 15.2 & 0.32 & 15 \\
\hline $\mathrm{Cr} 23$ & 0.954 & 0.1 & 19.2 & 177 & 66 & 14.4 & 0.33 & 10 \\
\hline $\mathrm{Cr} 24$ & 0.954 & 0.1 & 15.4 & 216 & 68 & 14.3 & 0.33 & 10 \\
\hline $\mathrm{Cr} 25$ & 0.942 & 0.8 & 15.8 & 187 & 55 & 9.5 & 0.35 & 10 \\
\hline Cr26 & 0.939 & 1.2 & 16.1 & 200 & 50 & 8.4 & 0.35 & 10 \\
\hline $\mathrm{Cr} 27$ & 0.938 & 1.3 & 15.4 & 227 & 50 & 8.2 & 0.36 & 10 \\
\hline $\mathrm{Cr} 28$ & 0.934 & 1.8 & 14.3 & 231 & 46 & 7.3 & 0.37 & 10 \\
\hline $\mathrm{ZN} 1$ & 0.959 & 0.1 & 13.6 & 174 & 71 & 14.9 & 0.34 & 10 \\
\hline $\mathrm{ZN} 2$ & 0.954 & 0.2 & 12.6 & 271 & 67 & 14.2 & 0.36 & 10 \\
\hline
\end{tabular}

Standard deviation of the data: $\mathrm{SD}(\rho)=10^{-3} \mathrm{~g} / \mathrm{cm}^{3} ; \mathrm{SD}(\xi)=0.1$ mole $\% ; \mathrm{SD}\left(M_{n}\right)=0.2-0.3 \mathrm{kDa} ; \mathrm{SD}\left(M_{w}\right)=2-3 \mathrm{kDa} ; \mathrm{SD}\left(X_{c}\right)=0.5 \% ; \mathrm{SD}\left(L_{c}\right)=0.2-0.3 \mathrm{~nm}$. 
relevant equations for computing the SAXS intensity profiles have been already reported by several authors [22, 23]. The disorder parameters were assessed from the best fitting of the model with experimental data, taking the $L_{c}$ and $L_{a}$ values as determined above, and assuming $\gamma_{c}=\gamma_{a}=\gamma$.

\section{RESULTS AND DISCUSSION}

\subsection{Molecular Characterization}

Table 1 displays the whole set of PE materials investigated in this work. This includes three classes of homopolymers and hexene copolymers: 1st generation chromium-oxide catalysis, $\mathrm{Cr} 1 \mathrm{X}$, 2nd generation chromium-oxide catalysis, $\mathrm{Cr} 2 \mathrm{X}$, and tandem-reactor Ziegler-Natta catalysis, ZNX. The materials are labeled according to decreasing density which results from co-unit concentration increase and/or molar weight distribution (MWD) broadening. The $\mathrm{X}$ code parameter indicates the material rank in the decreasing density classification.

According to a previous complete molecular characterization of polymer fractions from similar polymers via "Temperature Rising Elution Fractionation" [24], the following general rules can be put forward for the various polymers of the present study. The $\mathrm{Cr} 1$ and $\mathrm{Cr} 2$ polymer series are both unimodal and have the same co-unit distribution profile which decreases with increasing molar weight. However, $\mathrm{Cr} 2$ polymers have broader MWD than the Cr1 ones, notably on the high molar weight side of the distribution. This is likely to improve the occurrence of inter-crystalline tie molecules at equivalent density or crystallinity. $\mathrm{ZN}$ polymers have a bimodal MWD which results from to the tandem-reactor synthesis. This polymer series display a preferred incorporation of the co-units in the long chains which is another factor of improvement of inter-crystalline tie molecules. All these molecular peculiarities have conspicuous incidence on the stress crack resistance via the chain topology that will be evaluated through the study of the crystallization kinetics, the natural draw ratio, and the stacking disorder of the lamellar structure.

\subsection{Environmental Stress Cracking Resistance}

Figure 1 shows the ESCR dependency on density that directly reflects crystallinity. ESCR steadily increases with decreasing density, for every series. This is relevant to the increase of either co-unit content or broadening of the MWD on the high molar weight side which both promotes the occurrence of tie chain [24], due to crystallization considerations that will be discussed below. At equivalent density, i.e. $0.959 \mathrm{~g} / \mathrm{cm}^{3}$ and $0.954 \mathrm{~g} / \mathrm{cm}^{3}$, ESCR increases in the order $\mathrm{Cr} 13<\mathrm{Cr} 21<\mathrm{ZN} 1$ and $\mathrm{Cr} 15<\mathrm{Cr} 23<\mathrm{ZN} 2$, respectively. It is obvious that the greater ESCR of the $\mathrm{Cr} 2$ copolymers compared with the $\mathrm{Cr} 1$ ones is mainly due to the presence of longer chains (see $M_{w}$ values of Table 1) which improves the

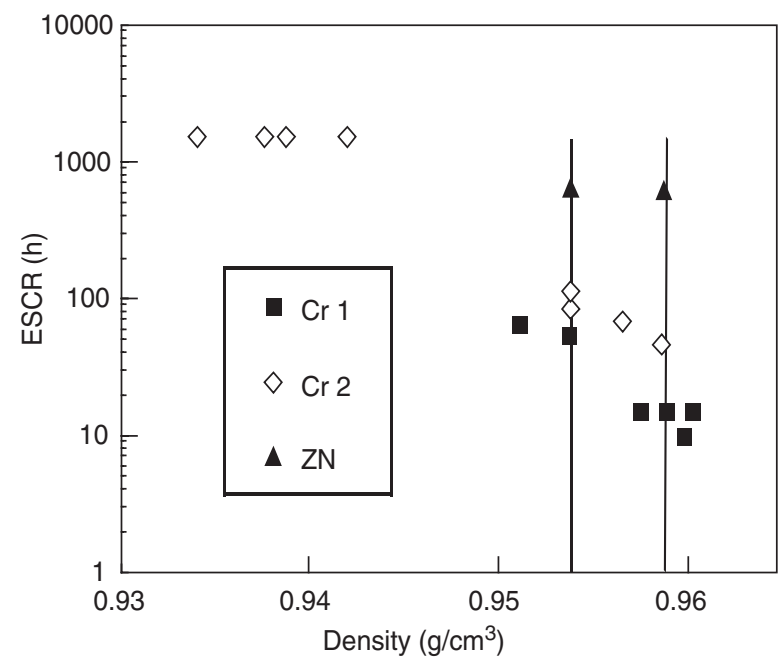

Figure 1

ESCR as a function of the materials density.

build up of tie chain [8] for reasons of chain dimensions with respect to crystal dimensions. Regarding the comparison between $\mathrm{Cr} 2$ and $\mathrm{ZN}$ copolymers, the preferred distribution of the co-units in the longer chains for the latter ones is a major factor of their excellent ESCR performances owing to the combined benefiting effect on tie chain density, in spite of lacking very long chains (see $M_{w}$ values of Table 1 ).

\subsection{Stepwise Isothermal Segregation}

Figure 2 shows a sketch of the molecular topology in semicrystalline polymers characteristic of low undercooling and large undercooling. The first isothermal crystallization step of the SIS treatment at low undercooling will result in predominant chain-folding with very few inter-crystalline tie chains (Fig. 2a). The subsequent cooling of the material that is carried out at larger undercooling should involve a high rate of random chain-folding and tie molecules (Fig. 2b).

Figure 3 shows the SIS ratio versus density. For every series, SIS ratio increases with decreasing density, indicating that the amount of chain species more prone to crystallize in the regime III increases in parallel. This is due to the increasing co-units content which hinders the regular chain folding due to the rejection of the co-units out of the crystal phase $[26,27]$. Regarding polymers of equivalent density in the three series, i.e. Cr13-Cr21-ZN1 and Cr15-Cr23-ZN2, the SIS ratio increases in the order $\mathrm{Cr} 1<\mathrm{Cr} 2<\mathrm{ZN}$. This means that regime III growth is increasingly favorable in the same order, with more frequent loose loops and tie chains. This stems from the broader MWD of the $\mathrm{Cr} 2$ series which promotes tie chains and loose loops. This phenomenon is yet more pronounced in the case of the $\mathrm{ZN}$ copolymers, due to 

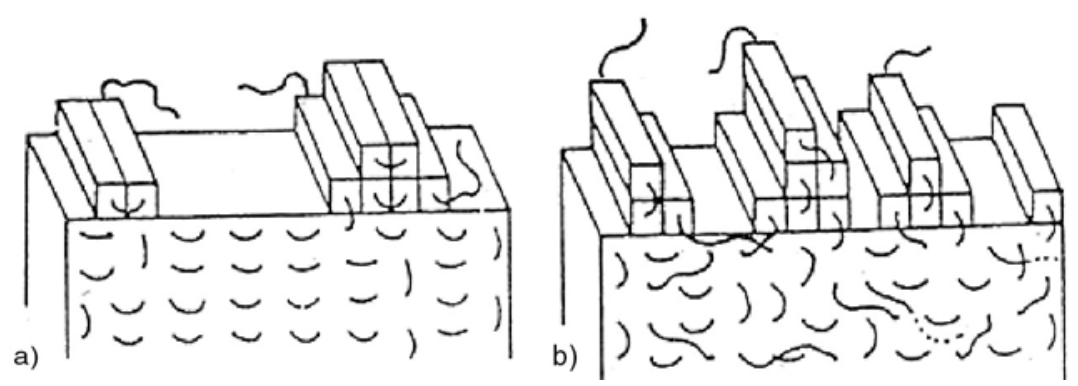

Figure 2

Schematic of the chain topology in semi-crystalline polymers depending on undercooling: a) low undercooling; b) large undercooling (Reproduced from [25] with permission of Springer Verlag, Copyright 1985).

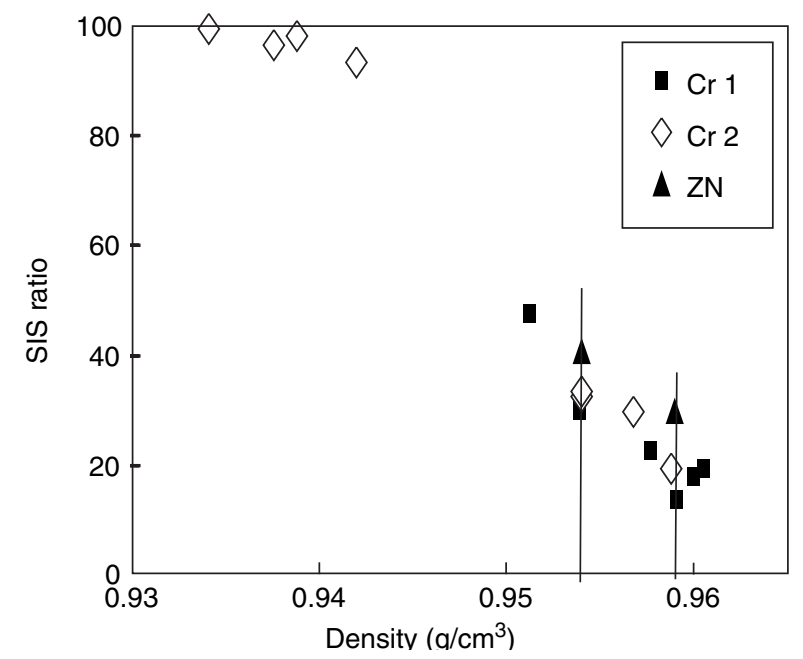

Figure 3

SIS ratio as a function of materials density.
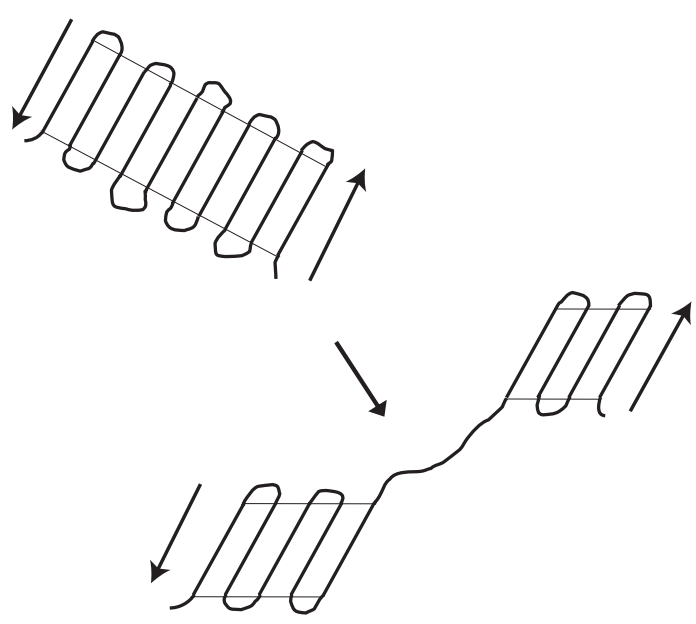

Figure 4

Sketch of the lamella fragmentation and chain unfolding processes under shear leading to the natural draw ratio in semi crystalline polymers. the preferred distribution of the co-units in the longer chains. The most striking point to be noticed is that the SIS ranking of the polymers at equivalent density is perfectly similar to that of the ESCR (Fig. 1). The SIS ratio thereby proves to be an efficient parameter for predicting the long-term mechanical behavior owing to the similar role of the chain topology on the two properties.

\subsection{Natural Draw Ratio}

Figure 4 shows a sketch of the fragmentation of an ideal crystalline lamellae and the subsequent chain unfolding from the fracture surfaces of the crystal blocks from which the NDR is originating $[4,19]$. Figure 5 shows the NDR versus density. For a given polymer series, NDR monotonously decreases with decreasing density. Considering the physical meaning of the NDR as judged from Figure 4, this is a very clear indication of an increasing concentration of loose loops and tie chains which prevent lamella fragmentation and chain unfolding. Close examination to Figure 2 enables understanding that the chain topology at the surface of the crystalline lamellae consisting of tie chains and lose loops is likely to hinder the lamella capability for fragmentation, as well as the chain unfolding process [19]. The major factor for this topological evolution of the polymers as a function of increasing co-unit content in the same series is the rejection of the co-units from the crystalline phase [26, 27]. At equivalent crystallinity, NDR drops in the order $\mathrm{Cr} 1<\mathrm{Cr} 2<\mathrm{ZN}$, a clear indication of reduced ability for lamella fragmentation and chain unfolding due to an increasing concentration of loose loops and tie chains. This finding is worth comparing with the ESCR and SIS ratio plots versus density which display the same trend: as previously pointed out in the case of the SIS ratio, the MWD broadening of the $\mathrm{Cr} 2$ series and 


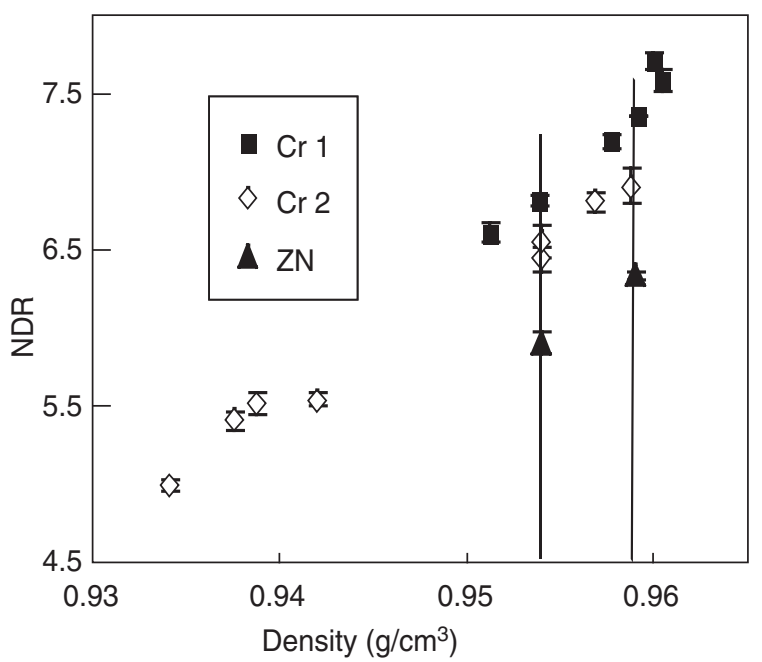

Figure 5

NDR as a function of materials density.

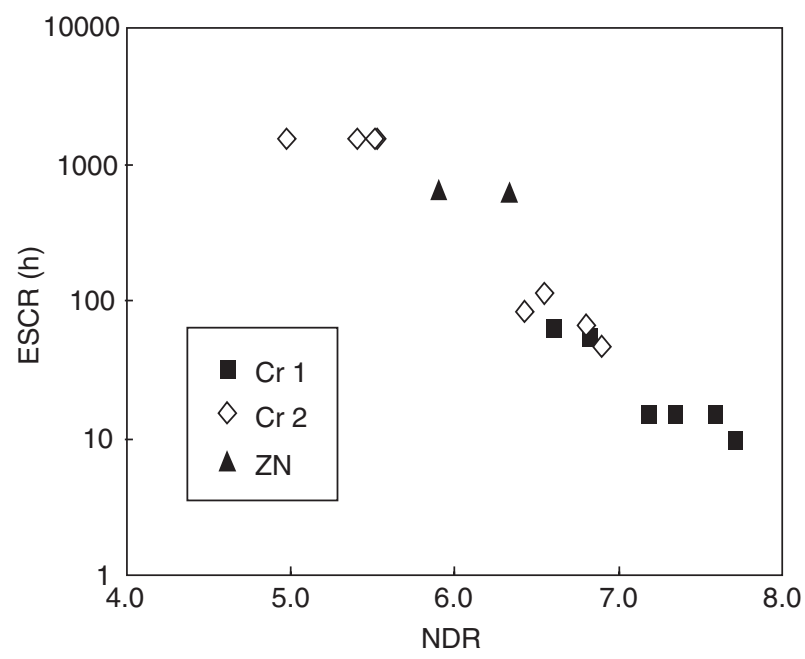

Figure 6

ESCR as a function of NDR for all the materials. the preferred distribution of the co-units in the longer chains of the $\mathrm{ZN}$ series are two modification factors of the chain topology through less regular chain folding and more intercrystalline molecular linkages.

A particular property of the NDR is its low standard deviation which makes it a highly discriminating parameter for PE materials. The ESCR versus NDR plot of Figure 6 results in an impressive univocal correlation irrespective of the synthesis process of the materials. This constitutes a universal predictive relationship for PE long-term behavior.

\subsection{Small-Angle X-ray Scattering}

The data from Table 1 show a steady decrease of the average crystal lamella thickness with decreasing density. This supports the crystallization trend already concluded from the SIS analysis, considering that a larger undercooling results in thinner and more defective crystals. In addition, thinner crystals are likely to promote higher density of tie molecule, according to Huang-Brown statistical model [9]. Similar trend applies for polymers of the three series at equivalent density, in the order $\mathrm{Cr} 1<\mathrm{Cr} 2<\mathrm{ZN}$, i.e. an increasing trend for growing thinner crystals that contribute to the ESCR improvement owing to a higher tie chain density.

Figure 7 shows an example of curve fitting of the Hosemann's model. The paracrystalline model provides distribution width parameter $\gamma$ which roughly increases with decreasing density. This is relevant to an increasing disorder in the lamellar stacking. This trend is corroborated by the parallel drop of parameter $N$. At equivalent density, an increasing trend is observed for $\gamma$ in the order $\mathrm{Cr} 1<\mathrm{Cr} 2<\mathrm{ZN}$, whereas $N$ decreases in parallel. The trend of increasing disorder in the lamellar stacking can be readily ascribed

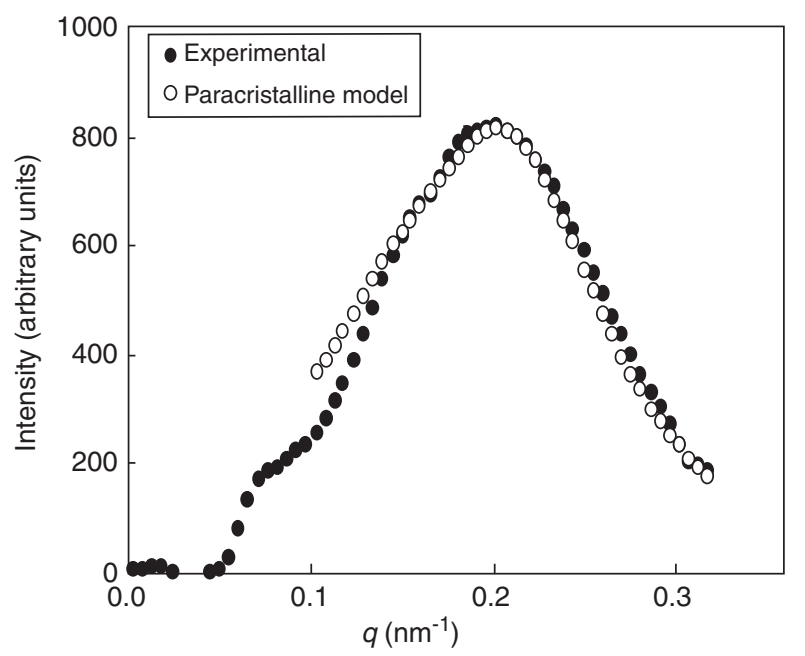

Figure 7

SAXS intensity profile and paracrystalline model fit for the Cr11 polymer $(q=$ scattering vector $=4 \pi \sin \theta / \lambda)$.

to the polymer molecular architecture which governs the propensity for large undercooling crystallization. Indeed, in addition to the thinning down of the crystals, large undercooling crystallization can be suspected to reduce the lateral development of the crystalline lamellae in both width and length, involving a reduction of the lamella capability for regular stacking. This morphological trend connected with a a change in crystallization capability is supported by electron microscopic observations evidencing a gradual degradation of the well defined lamellar structure of polyethylene crystals into fringed micelles with decreasing density [28]. 


\section{CONCLUSION}

ESCR has been shown to directly depend on PE capability for generating disorder at various scale levels in the semicrystalline microstructure. This has been demonstrated by the following findings that go along with the ESCR increase:

- increasing propensity of PE materials for large undercooling crystallization as judged from SIS ratio;

- increasing resistance to plastic instability as judged from natural draw ratio;

- increasing stacking disorder trend as judged from smallangle X-ray scattering.

The two former experimental approaches displayed very good correlation with density and proved to be very quick and convenient probes for prediction of PE long-term behavior. SAXS only provides trend between stacking disorder and ESCR due to the relatively low sensitivity of the disorder parameters, but this approach proved to be much instructive about the chain topology incidence on the structural organization.

The evolution of ESCR, SIS ratio, NDR and SAXS disorder as a function of density in a given polymer series or as a function of the synthesis process at equivalent density can be connected with the molecular architecture modifications, namely the molar weight distribution as well as the co-unit concentration and distribution.

The high discrimination potential of the natural draw ratio makes it a universal predictive parameter for long-term mechanical behavior of PE-based materials.

\section{REFERENCES}

1 Series of International Conferences have been running for more than three decades, at roughly one per year rate: "International Gas Research Conferences", org.: Gas Technology Institute, Des Plaines IL, USA; "Plastics Pipes", org.: Institute of Materials, London, UK; "Plastic Pipe Fuel Gas Symposia", org: Plastics Pipe Institute, Washington D.C., USA; "Plastic Fuel Gas Pipe Symposium", org.: American Gas Association, Washington D.C., USA.

2 Friedrich, K. (1983) Crazes and shear bands in semi-crystalline thermoplastics, Adv. Polym. Sci. 52/53, 225-227.

3 Plummer, C.J.G. (2004) Microdeformation and fracture in bulk polyolefins, Adv. Polym. Sci. 169, 75-119.

4 Meinel, G., Peterlin, A. (1971) Plastic deformation of polyethylene. II. Change of mechanical properties during drawing, J. Polym. Sci. A2 9, 67-83.

5 Peterlin, A., Meinel, G. (1971) Small-angle X-ray diffraction studies of plastically deformed polyethylene. III. Small draw ratios, Makromolecul. Chem. 142, 227-240.

6 Shah, A., Stepanov, E.V., Klein, M., Hiltner, A., Baer, E. (1998) Study of polyethylene pipe resins by a fatigue test that simulates crack propagation in a real pipe, J. Mater. Sci. 33, 3313-3319.

7 Plummer, C.J., Goldberg, A., Ghanem, A. (2001) Micromechanisms of slow crack growth in polyethylene under constant tensile loading, Polymer 42, 9551-9564.
8 Huang, Y.-L., Brown, N. (1988) Effect of molecular weight on slow crack growth in linear polyethylene homopolymers, J. Mater. Sci. 23, 3648-3655.

9 Huang, Y.-L., Brown, N. (1991) Dependence of slow crack growth in polyethylene on butyl branch density: morphology and theory, J. Polym. Sci. A2 29, 129-137.

10 Rose, L.J., Channell, A.D., Frye, C.J., Capaccio, G. (1994) Slow crack growth in polyethylene: a novel predictive model based on the creep of craze fibrils, J. Appl. Polym. Sci. 54, 2119-2124.

11 Hubert, L., David, L., Seguela, R., Vigier, G., CorfiasZuccall, C., Germain, Y. (2002) Physical and mechanical properties of polyethylene for pipes in relation to molecular architecture. II. Short-term creep of isotropic and drawn materials, J. Appl. Polym. Sci. 84, 2308-2317.

12 Lagaron, J.M., Dixon, N.M., Gerrard, D.I., Reed, W., Kip, B.J. (1998) Cold-drawn material as model material for the environmental stress cracking in polyethylene. Raman spectroscopy study of molecular stress induced by macroscopic strain in drawn polyethylenes and their relation to environmental stress cracking, Macromolecules 31, 5845-5852.

13 Hosoda, S., Uemura, A. (1992) Effect of the structural distribution on the mechanical properties of linear low-density polyethylenes, Polymer J. 24, 939-949.

14 Gueugnaut, D., Rousselot, D. (1999) Detection of divergences in polyethylene resins fabrication by means of the modified stepwise isothermal segregation technique, J. Appl. Polym. Sci. 73, 2103-2112.

15 Wunderlich, B. (1973) Macromolecular Physics; Vol.1: Crystal Structure, Morphology, Defects. Academic Press, New York.

16 Hoffman, J.D., Guttman, C.M., Di Marzio, E.A. (1979) On the problem of crystallisation of polymers from the melt with chain folding, Faraday Discuss. Chem. S. 68, 177-197.

17 Hoffman, J.D., Miller, R.L. (1997) Kinetics of crystallization from the melt and chain folding in polyethylene fractions revisited: theory and experiment, Polymer 38, 3151-3212.

18 Ward, I.M. (1980) Mechanical Properties of Solid Polymers. Wiley Interscience, New York.

19 Tarin, P.M., Thomas, E.L. (1979) The role of inter- and intralinks in the transformation of folded chain lamellae into microfibrils, Polym. Eng. Sci. 19, 1017-22.

20 Hosemann, R., Bagchi, S.N. (1962) Direct Analysis of Diffraction by Matter. North-Holland publishing Comp., Amsterdam.

21 Reinhold, C., Fischer, E.W., Peterlin, A. (1964) Evaluation of small-angle X-ray scattering of polymers, J. Appl. Phys. 35, $71-74$

22 Hall, H., Mahmoud, E.A., Carr, P.D., Geng, Y.D. (1987) Small-angle X-ray scattering by crystalline polymer fibers. 1. Experimental method and investigation of the linear paracrystalline model, Colloid. Polym. Sci. 265, 383-93.

23 Annadurai, V., Gopalkrishne, R., Siddaramaiah, R., Somashekar, R. (2000) Small angle X-ray scattering in nylon 6 using exponential distribution of phase lengths, Polymer 41, 5689-5694.

24 Hubert, L., David, L., Seguela, R., Vigier, G., Degoulet, C., Germain, Y. (2001) Physical and mechanical properties of polyethylene for pipes in relation to molecular architecture. I. Microstructure and crystallization kinetics, Polymer 42, 8425-8434.

25 Monasse, B., Haudin, J.M. (1985) Growth transition and morphology changes in polypropylene, Colloid. Polym. Sci. 263, 822-831. 
26 Seguela, R., Rietsch, F. (1986) Tensile drawing behaviour of ethylene/ $\alpha$-olefin copolymers: influence of the co-unit concentration, Polymer 27, 703-708.

27 Gaucher, V., Seguela, R. (1994) Phase partitioning of the chain defects in ethylene-butene in the framework of the crystalline chain kink model, Polymer 35, 2049-2055.
28 Bensason, S., Minick, J., Moet, A., Chum, S., Hiltner, A., Baer, E. (1996) Classification of homogeneous ethylene octene copolymers based on comonomer content, J. Polym. Sci. A2 34, 1301-1315.

Final manuscript received in August 2006 